\title{
Suppression of neuroinflammation in forebrain-specific Cdk5 conditional knockout mice by PPARy agonist improves neuronal loss and early lethality
}

\author{
Elias Utreras ${ }^{1,4}$, Ryusuke Hamada², Michaela Prochazkova ${ }^{1}$, Anita Terse ${ }^{1}$, Satoru Takahashi ${ }^{3}$, Toshio Ohshima ${ }^{2 *}$
} and Ashok B Kulkarni ${ }^{1 *}$

\begin{abstract}
Background: Cyclin-dependent kinase 5 (Cdk5) is essential for brain development and function, and its deregulated expression is implicated in some of neurodegenerative diseases. We reported earlier that the forebrain-specific Cdk5 conditional knockout (CKO) mice displayed an early lethality associated with neuroinflammation, increased expression of the neuronal tissue-type plasminogen activator (tPA), and neuronal migration defects.

Methods: In order to suppress neuroinflammation in the CKO mice, we first treated these mice with pioglitazone, a PPARY agonist, and analyzed its effects on neuronal loss and longevity. In a second approach, to delineate the precise role of tPA in neuroinflammation in these mice, we generated Cdk5 CKO; tPA double knockout (dKO) mice.

Results: We found that pioglitazone treatment significantly reduced astrogliosis, microgliosis, neuronal loss and behavioral deficit in Cdk5 CKO mice. Interestingly, the dKO mice displayed a partial reversal in astrogliosis, but they still died at early age, suggesting that the increased expression of tPA in the CKO mice does not contribute significantly to the pathological process leading to neuroinflammation, neuronal loss and early lethality.
\end{abstract}

Conclusion: The suppression of neuroinflammation in Cdk5 CKO mice ameliorates gliosis and neuronal loss, thus suggesting the potential beneficial effects of the PPARY agonist pioglitazone for the treatment for neurodegenerative diseases.

Keywords: Neuroinflammation, Cdk5, Pioglitazone, tPA, Cdk5 conditional knockout mice

\section{Background}

Cyclin-dependent kinase 5 (Cdk5) is an atypical member of the cyclin-dependent kinase family, whose other members are key regulators of the cell cycle [1]. Cdk5 is ubiquitously expressed, and it is mainly active in post-mitotic neurons, where its activators $\mathrm{p} 35$ and $\mathrm{p} 39$ are predominantly expressed $[2,3]$. Cdk5 is a proline-directed serine/ threonine kinase that phosphorylates a consensus sequence of $(\mathrm{S} / \mathrm{T}) \mathrm{PX}(\mathrm{K} / \mathrm{H} / \mathrm{R})$ in many target proteins [4]. Cdk5

\footnotetext{
* Correspondence: ohshima@waseda.jp; ak40m@nih.gov

${ }^{2}$ Department of Life Science and Medical Bioscience, Waseda University, Tokyo, Japan

${ }^{1}$ Functional Genomics Section, Laboratory of Cell and Developmental Biology, National Institute of Dental and Craniofacial Research, National Institutes of Health, Bethesda, MD, USA

Full list of author information is available at the end of the article
}

phosphorylates many cytoskeletal elements, signaling molecules, ions channels, nociceptors and regulatory proteins that participate in the normal function of the brain and also during neurodegenerative disorders $[1,3,5,6]$. A detailed analysis of Cdk5 knockout mice, which display perinatal lethality and extensive neuronal migration defects, revealed that Cdk5 serves as key regulator of neuronal migration, neurite outgrowth, axonal pathfinding and dendrite development $[7,8]$. To circumvent the perinatal lethality of Cdk5 knockout mice, we previously generated Cdk5 conditional knockout (cKO) mice that lacked Cdk5 expression in the forebrain $[9,10]$. At three months of age, these mice displayed an early lethality associated with neuroinflammation, increased expression of the neuronal tissue-type plasminogen activator ( $\mathrm{tPA}$ ) and tumor necrosis 
factor- $\alpha$ (TNF- $\alpha)$ [10]. Since PPAR $\gamma$ agonist pioglitazone has been reported to effectively suppress neuroinflammation in an Alzheimer's disease (AD) mouse model [11] and it also had beneficial effects in mouse models of multiple sclerosis (ALS) [12-15] and Parkinson's disease (PD) [16], we treated cKO mice with pioglitazone, and analyzed its effects on longevity, neuronal loss, and studied the timing of activation of astrocytes and microglial cells by using immunofluorescence against anti-GFAP and Iba1, respectively. In a second approach, we generated Cdk5 and tPA double knockout (dKO) mice to observe effects of the loss of tPA expression on neuroinflammation, astrogliosis and longevity. Our studies revealed the beneficial effects of pioglitazone treatment on the cKO mice. However, the loss of tPA expression in the forebrain of the cKO mice did not ameliorate neuroinflammation and early lethality in these mice.

\section{Methods}

\section{Animals and experimental protocols}

$\mathrm{Cdk}^{\mathrm{f} / \mathrm{f}}$ mice [9] were crossed with CamKII-Cre ${ }^{+}$transgenic mice [17] to delete Cdk5, specifically in forebrain adult neurons and these mice were named Cdk5 cKO1 mice [10]. To avoid possible effects of Cre-mediated deletion of the noncoding sequence of flanking genes located in the proximity of $C d k 5$ gene, Accn 3 and Slc4a2, in Cdk5 cKO1 mice, we crossed $\mathrm{Cdk}^{\mathrm{f} /-}, \mathrm{Cdk}^{+/-}$[7], and CamKII$\mathrm{Cre}^{+}$mice to generate $\mathrm{Cdk}_{5}{ }^{\mathrm{f} /-}$; $\mathrm{CamKII-Cre}{ }^{+}$mice, named Cdk5 cKO2 mice [10]. Additionally, we crossed tPA knockout mice [18] with $\mathrm{Cdk} 5$ cKO2 mice to generate double knockout mice: Cdk5 cKO; tPA KO named dKO mice (Additional file 1: Figure S1). The genotype of each mouse was determined by the PCR from DNA obtained from tail biopsies. These studies were performed in compliance with the National Institutes of Health Guidelines on the Care and Use of Laboratory and Experimental Animals. All experimental procedures were approved by the Animal Care and Use Committee of the National Institute of Dental and Craniofacial Research, NIH and the Waseda University.

\section{Antibodies and materials}

Anti-NeuN mouse monoclonal antibody (clone A60, 1:500, Chemicon, Temecula, CA, USA), anti-GFAP rabbit polyclonal antibody (1:500, Dako, Carpinteria, CA, USA), and anti-Iba1 rabbit polyclonal antibody (1:500, Wako, Richmond, VA, USA), and anti-Cdk5 (308-CDK5 Phosphosolutions, Aurora, CO, USA) were used for immunohistochemical analysis of Cdk5 cKO and control mice. Anti-Cdk5 (C8 and J3), anti-p35 (C19), and secondary antibodies (HRP-conjugated goat anti-mouse, anti-rabbit antibodies) from Santa Cruz Biotechnology, Inc. (Santa Cruz, CA, USA), GFAP antibody from Cell Signaling Technology (Beverly, MA, USA), anti-NeuN antibody from Millipore (Temecula, CA, USA), histone $\mathrm{H} 1$ and $\alpha$ tubulin antibody from Sigma (St. Louis, MO, USA) were used for the Western blot analysis of Cdk5 $\mathrm{cKO} 2$ and control mice.

\section{PPARy agonist pioglitazone treatment}

Pioglitazone hydrochloride was obtained from TOCRIS Bioscience (Bristol, UK). The mice were fed rodent chow ad libitum that was supplemented with $350 \mathrm{ppm}$ pioglitazone hydrochloride from P30. The final dosage of the drug was calculated to $58.3 \mathrm{mg} / \mathrm{kg} /$ day of pioglitazone based on an average daily food consumption of $5 \mathrm{~g}$ of chow per mouse.

\section{Histological analyses}

After intraperitoneal injections of avertin $(250 \mathrm{mg} / \mathrm{kg}$, Sigma, St. Louis, MO, USA) mice were transcardially perfused with freshly prepared $4 \%$ paraformaldehyde in $0.1 \mathrm{~mol} / \mathrm{L}$ cacodylate buffers, $\mathrm{pH} 7.4$ and brains were removed and embedded in a gelatin matrix (NeuroScience Associates, Knoxville, TN, USA). Free-floating sections ( $35 \mu \mathrm{m}$ in thickness) were cut on a microtome and processed for staining. Histological analyses with cresyl violet (Nissl stain, Molecular Probe, Eugene, OR, USA), aminocupric staining, and immunohistochemistry against antiNeuN (Chemicon, Temecula, CA, USA) and anti-GFAP (DAKO, Glostrup, Denmark) were performed as previously described [10]. The staining specificity of these antibodies was assessed by omission of the primary antibodies.

\section{Immunohistochemistry}

Cdk 5 cKO1 and control mice were perfusion-fixed with $4 \%$ paraformaldehyde; thereafter, their brains were removed from their skulls and immersed in the same fixative, which was done overnight at $4{ }^{\circ} \mathrm{C}$. The brains were then equilibrated in $20 \%$ sucrose and embedded in an optimal cutting temperature (OCT) compound. Cryosections of $14-\mu \mathrm{m}$ thickness were cut with a frozen microtome. The immunostaining of sections was performed as previously described [8]. Briefly, after the blocking of a non-specific binding of antibodies, the sections were incubated with the primary antibodies, which were diluted in $\mathrm{PBS} / 0.01 \%$ Triton X-100, overnight at $4^{\circ} \mathrm{C}$. They were then washed three times with PBS and incubated with Alexa-Fluor $488(1: 1,000)$ or Alexa-Fluor $568(1: 1,000)$ (Molecular Probes, Eugene, OR, USA) secondary antibodies for one hour. After three further washes with PBS, the sections were embedded in Vectashield mounting media (Vector, Burlingame, CA, USA). Images were obtained by a CCD camera (DP70, Olympus).

\section{Cell count}

Neurons, activated astrocytes and microglia were counted in coronal brain sections. All labeled cells within three 
squares of $0.15 \mathrm{~mm}^{2}$ each were counted in coronal sections using a BX-51 Olympus (Tokyo, Japan) microscope (200x magnification: $10 \times$ ocular and $20 \times$ objective) as described [19]. Six sections from each brain were analyzed and averaged. The mean value from the combined data of at least three animals per time point was calculated. To exclude false-positives, only GFAP- or Iba1-positive signals merged with nuclear staining by diamidino-2phenylindole (DAPI) staining were counted.

\section{Neuronal size}

To evaluate neuronal size, we stained coronal sections from these mice with NeuroTrace ${ }^{\mathrm{Ta}} 530 / 615$ (red fluorescent Nissl stain from Molecular Probe, Eugene, OR, USA) and DAPI. Images were obtained by a confocal microscope (FV1000, Olympus, Tokyo, Japan). Sizes of CA1 pyramidal neurons (more than 50 neurons from three mice) were measured by Image-J.

\section{Western blot analysis}

Protein extracts were obtained from brain cortex of control, Cdk5 cKO2, and dKO mice at P17 in T-PER buffer (Pierce, Rockford, IL, USA) with protease inhibitor cocktail tablets and phosphatase inhibitor cocktail tablets, PhosSTOP (Roche Diagnostic, Indianapolis, IN, USA), and Western blot analyses were performed as previously reported [20]. Protein concentration of the supernatant was determined using the Bradford Protein Assay (Bio-Rad, Hercules, CA, USA). Proteins were separated in 4 to $12 \%$ or 3 to $8 \%$ SDS-PAGE gels and transferred to nitrocellulose membranes (Invitrogen, Carlsbad, CA, USA). The membranes were soaked in a blocking buffer (5\% nonfat dry milk in PBS with 0.05\% Tween-20 (PBST)) for one hour at room temperature, and then incubated overnight at $4^{\circ} \mathrm{C}$, with the appropriate primary antibody diluted in the blocking buffer. The membranes were washed in PBST and incubated for one hour at room temperature with the secondary antibodies diluted in blocking buffer. Immunoreactivity was detected by SuperSignal West Pico or Dura Chemiluminescent Substrate (Thermo Scientific, Rockford, IL, USA). Membranes were stripped for 15 minutes at room temperature with Re-blot Plus Strong Solution (Chemicon, Temecula, CA, USA). They were retested with $\alpha$-tubulin antibodies to normalize for protein loading. The optical densities of the bands were quantified using an image analysis system with Scion Image Alpha 4.0.3.2 software (Scion Corporation, Frederick, MD, USA).

\section{Cdk5 kinase activity assay}

As reported earlier, $300 \mu \mathrm{g}$ of protein from brain cortex of 17-day-old control, Cdk5 cKO2, and dKO mice, were dissolved in T-PER buffer, and they were immunoprecipitated using $4 \mu \mathrm{g}$ of anti-Cdk5 (C8) antibody (Santa
Cruz Biotechnology, Inc., Santa Cruz, CA, USA) [21]. Immunoprecipitated proteins (IP) were washed three times in cold PBS, and twice in kinase buffer $(20 \mathrm{mM}$ Tris $\mathrm{HCl}$ (pH 7.4), $10 \mathrm{mM} \mathrm{MgCl}_{2}, 1 \mathrm{mM}$ EDTA). Then, the IP was mixed with the kinase assay mixture $(100 \mathrm{mM}$ Tris $\mathrm{HCl}(\mathrm{pH} 7.4), 50 \mathrm{mM} \mathrm{MgCl}_{2}, 5 \mathrm{mM}$ EDTA, and $5 \mathrm{mM}$ DTT) plus 5 units of $\left(\gamma^{32}\right)$-ATP, and using $5 \mu \mathrm{g}$ of histone $\mathrm{H} 1$ as a substrate. The kinase assays were carried out for 30 minutes at $30^{\circ} \mathrm{C}$, and the kinase activity reaction was stopped by adding $5 \times$ sodium dodecyl sulfate sample buffer and boiling for ten minutes at $70^{\circ} \mathrm{C}$. Kinase reaction was electrophoresed on a 4 to $20 \%$ polyacrylamide gel, and then gels were exposed to X-ray films, for 1 to 3 hours at $-80^{\circ} \mathrm{C}$. The incorporation of $\mathrm{P}^{32}$ to histone $\mathrm{H} 1$ was quantified to measure band intensity using Scion Image Alpha 4.0.3.2 software (Scion Corporation, Frederick, MD, USA).

\section{RNA isolation and real-time PCR}

Total RNAs were obtained from brain cortex of 17-dayold control, Cdk5 cKO2, and dKO mice. RNA was isolated from tissue using TRIzol $^{\circ}$ reagent (Invitrogen, Carlsbad, CA, USA), according to the manufacturer's instructions. Following TURBO DNA-free (Ambion, Austin, TX, USA) digestion of the total RNA sample, oligo (dT)-primed synthesis of cDNA from $3 \mu \mathrm{g}$ of total RNA was made using SuperScript ${ }^{\text {ti }}$ III Reverse Transcriptase (Invitrogen, Carlsbad, CA, USA) to remove contaminated genomic DNA. For detection of CD68, TNF- $\alpha$, interleukin 6 (IL-6), interferon- $\gamma$ (IFN- $\gamma)$, interleukin $1 \beta$ (IL-1 $\beta)$, transforming growth factor $\beta 1$ (TGF- $\beta 1$ ), oncostatin $\mathrm{M}$ (OSM) and leukemia inhibitory factor (LIF) mRNA, we used real-time PCR, and the following reaction mixture was used for these PCR samples: $1 \mathrm{xIQ}^{\mathrm{m}}$ Sybr ${ }^{\circ}$ Green Super Mix (BioRad, Hercules, CA, USA), 100 to $200 \mathrm{nM}$ of each primer and $1 \mu \mathrm{l}$ of cDNA. cDNA was amplified and analyzed in triplicate using Opticon Monitor Chromo 4 (Bio-Rad, Hercules, CA, USA). The following primers were used to amplify and measure the amount of mouse mRNA by real-time PCR: CD68 sense 5' -ACC GCC ATG TAG TCC AGG TA-3' and antisense $5^{\prime}$-ATC CCC ACC TGT CTC TCT CA-3'; Cdk5 sense 5'-GGC TAA AAA CCG GGA AAC TC-3' and Cdk5 antisense 5' -CCA TTG CAG CTG TCG AAA TA-3'; TNF- $\alpha$ sense 5' -GAT CTC AAA GAC AAC CAA CTA GT-3' and antisense 5' ${ }^{\prime}$-CTC CAG CTG GAA GAC TCC TCC CAG -3'; IL-6 sense 5' -CTG CAA GAG ACT TCC ATC CAG TT -3' and antisense 5'-GAA GTA GGG AAG GCC GTG G -3'; IFN- $\gamma$ sense 5'-TCA AGT GGC ATA GAT GTG GAA GAA- $3^{\prime}$ and antisense 5'-TGG CTC TGC AGG ATT TTC ATG-3'; IL-1 $\beta$ sense 5'-CAA CCA ACA AGT GAT ATT CTC CAT G-3' and antisense 5'-GAT CCA CAC TCT CCA GCT GCA-3', TGF- $\beta 1$ sense 5'-GCA GTG GCT GAA CCA AGG AG$3^{\prime}$ and antisense 5'-CCC GAC GTT TGG GGC TGA 
TC-3'; OSM sense 5' ${ }^{\prime}$-TGT GGC TTT CTC TGG GGA TAC-3' and antisense 5'-GAA GGT CTG ATT TTG CGG GAT-3'; LIF sense 5'-ACG GCA ACC TCA TGA ACC A-3' and antisense 5'-GGA AAC GGC TCC CCT TGA-3'. The gene expression level was normalized against S29 expression using S29 sense 5'-GGA GTC ACC CAC GGA AGT TCG G-3' and antisense 5' -GGA AGC ACT GGC GGC ACA TG-3'. Real-time PCR reactions were run in triplicate and repeated three times.

\section{Statistical analysis}

All of the experiments were performed a minimum of three times. The statistical evaluation was done with GraphPad Prism software, version 4.0 (GraphPad, San Diego, CA, USA). The significant differences between the experiments were assessed by univariate ANOVA (more than two groups) or unpaired $t$-tests (two groups). ANOVA was followed by $t$-tests using a Bonferroni $\alpha$ correction or Dunett's test, where $\alpha$ was set to 0.05 .

\section{Results \\ Inflammatory reactions precede neuronal loss and early lethality in Cdk5 cKO mice}

As reported earlier, we generated two lines of Cdk5 conditional knockout mice: Cdk5 cKO1 $\left(\mathrm{Cdk}^{\mathrm{f} / \mathrm{f}}\right.$; CamKII$\left.\mathrm{Cre}^{+}\right)$and $\mathrm{Cdk} 5 \mathrm{cKO} 2\left(\mathrm{Cdk}^{\mathrm{f} /-}\right.$, CamKII-Cre $\left.{ }^{+}\right)$mice [10] (see, Additional file 1: Figure S1). Both Cdk5 cKO1 and cKO2 mice were born with an expected Mendelian frequency. As described earlier [10] $20 \%$ to $30 \%$ of Cdk5 cKO1 mice lived for more than three months; however $95 \%$ of the Cdk5 cKO2 mice died within one month after birth. We had earlier observed that the neuroinflammation and neuronal loss occurred at P90 but not at P21 in Cdk 5 cKO1 mice as compared to $\mathrm{Cdk} 5^{\mathrm{f} / \mathrm{f}}$ controls [10]. To define the precise timing of the onset of this neuroinflammation, we analyzed the inflammatory reactions in the brain of Cdk5 cKO1 mice by immunohistochemical staining. NeuN, GFAP and Iba1 were used as markers for neurons, activated astrocytes and microglia, respectively. At P21, we did not notice any increase in the GFAP-positive or Iba1-positive cells (Additional file 2: Figure S2A-E). At P30, we observed increased GFAPpositive cells and Iba1-positive cells in the brain cortex of Cdk5 cKO1 mice (Additional file 2: Figure S2F-J); however, there was no apparent decrease in the NeuN-positive cells, thus indicating that neuronal loss did not occur at this age. Moreover, we evaluated whether the deficient of Cdk5 in mice produced pathological changes such as degenerative neurons or change in neuron size. We analyzed different areas of control and Cdk5 cKO1 mice at P30 and we performed amino-cupric silver and Nissl stain to evaluate those parameters. We found an increased number of amino-cupric silver positive cells in both cerebral cortex and striatum of Cdk5 cKO1 as compared with control mice (Additional file 3: Figure S3A). At this stage, no difference in neuronal size was found in CA1 pyramidal neurons between $\mathrm{Cdk} 5 \mathrm{cKO} 1$ and control littermates (Additional file 3: Figure S3B).

\section{Pioglitazone, PPARY agonist, treatment improved neuronal loss in Cdk5 cKO1 mice}

Because we observed neuroinflammation in the Cdk5 cKO1 cortex at P30, we hypothesized that the inflammatory reactions were the cause of neuronal loss [10]. To test this hypothesis, we treated the Cdk5 cKO1 mice with the PPARY agonist pioglitazone that suppressed inflammation in the brain of an AD mouse model [11]. We started the pioglitazone treatment at P30 and analyzed the results of this treatment at P60 and P90. We compared the survival of the treated and untreated Cdk5 cKO1 mice. At $\mathrm{P} 60,76 \%$ of the Cdk5 cKO1 mice (16/ 21) survived as compared to $33 \%$ of the untreated mice (13/39) $(P<0.01 ; P=0.0080$ in Log-rank test and $P=$ 0.0086 in Wilcoxon test) (Figure 1A). At P90, a similar higher survival rate was observed in the treated Cdk5 cKO1 mice (Additional file 4: Figure S4A). We next compared the body weight gain in the male mice from both the groups. At $\mathrm{P} 60$, untreated $\mathrm{Cdk} 5$ cKO1 mice showed reduced body weight whereas the treated $\mathrm{Cdk} 5 \mathrm{cKO} 1$ mice recovered from the body weight loss (control $=23.62 \pm$ $0.68 \mathrm{~g}$, untreated Cdk5 $\mathrm{cKO} 1$ mice $=17.79 \pm 1.11 \mathrm{~g}$, and treated Cdk5 cKO1 mice $=21.79 \pm 0.53 \mathrm{~g}$ ) (Figure 1B). Improved body weight gain was also observed in the treated Cdk5 cKO1 mice at P90 (Additional file 4: Figure S4B). Since we had earlier observed neuronal loss in the olfactory bulb, brain cortex, striatum and hippocampus of Cdk5 cKO1 mice at P90 [10], we analyzed cell densities of neurons, reactive astrocytes and microglia by using NeuN, GFAP, and Iba1 markers, respectively. At P60, we observed significant neuronal loss in all regions in the untreated Cdk5 cKO1 mice, whereas neuronal loss was significantly reversed in the treated Cdk5 cKO1 mice (Figure 1C-E). We also found a decrease in the number of GFAPpositive astrocytes and Iba1-positive microglia in the treated Cdk5 cKO1 mice, as compared to the untreated mice (Figure 1C-G). Improvement in neuronal loss and suppressed neuroinflammation were also found in the treated Cdk5 cKO1 mice at P90 (Additional file 4: Figure S4C-G). The data indicate that pioglitazone suppressed neuroinflammation and partially rescued neuronal loss in Cdk5 cKO1 mice, suggesting that neuroinflammation caused neuronal loss in the Cdk5 cKO1 mouse brain. As described previously [10], untreated Cdk5 cKO1 mice showed retraction of their limbs toward their trunks when suspended by their tail. Therefore, we analyzed whether pioglitazone treatment can improve the neurological deficit observed in Cdk5 cKO1 mice. We found that this phenotype was partially improved in treated Cdk5 cKO1 

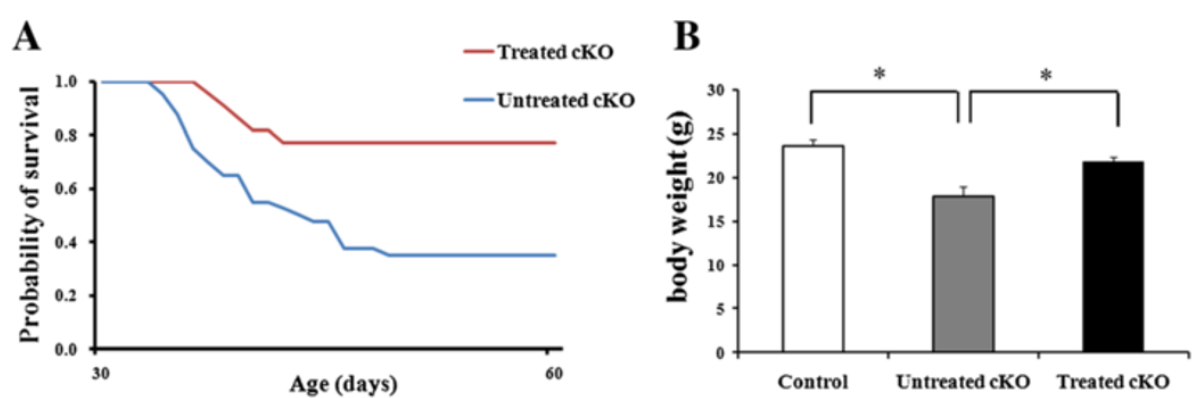

C
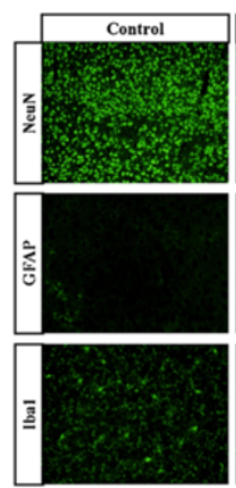

D
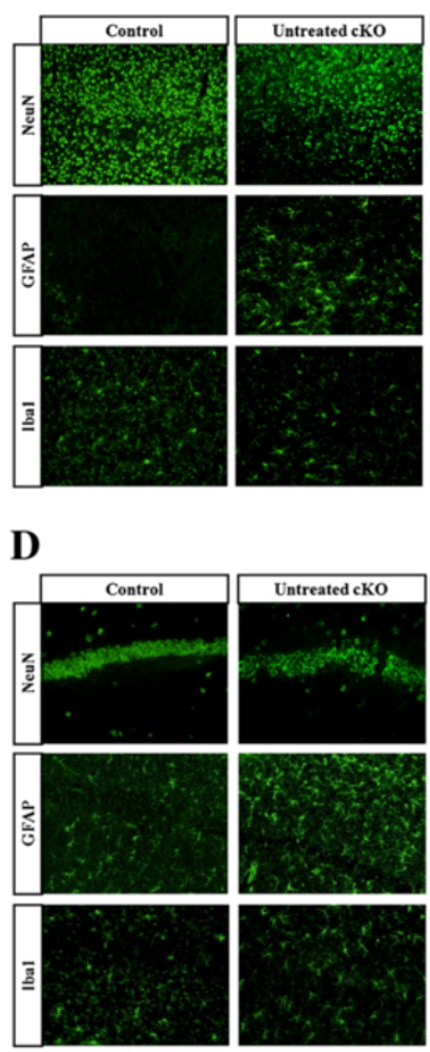

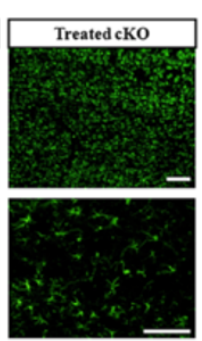

$\mathbf{E}$
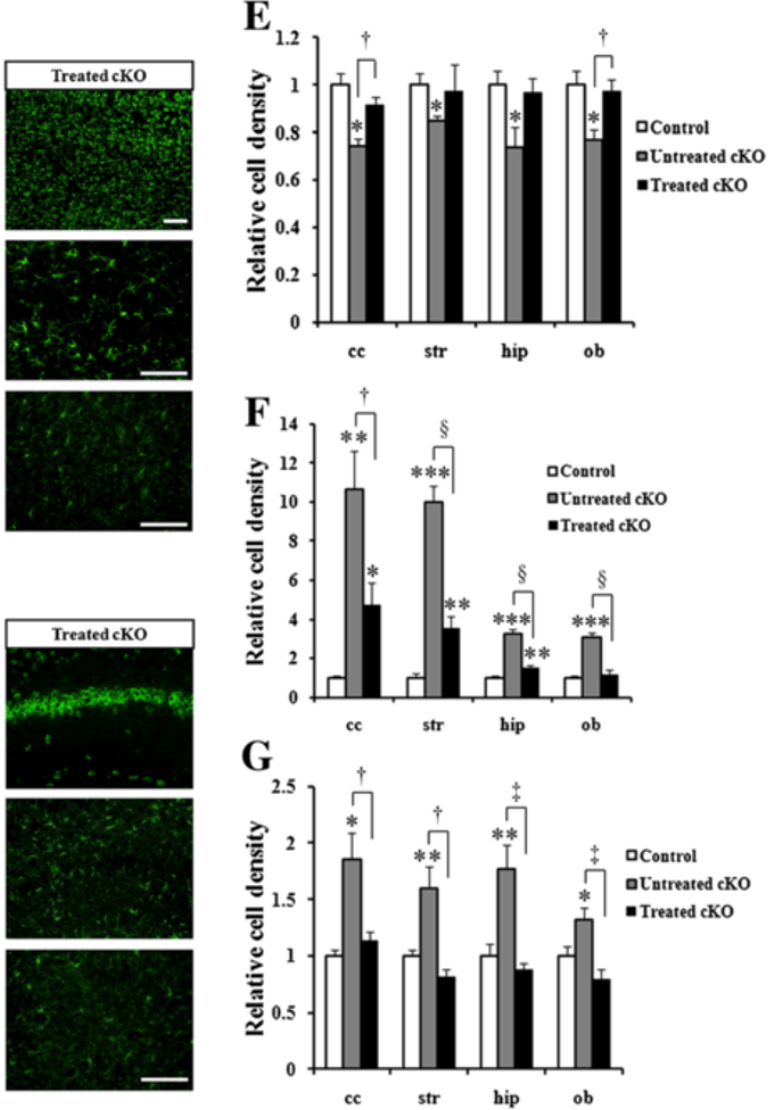

Figure 1 PPARy agonist pioglitazone suppressed inflammation and partially reversed neuronal loss in Cdk5 cKO1 mice. (A) Survival curves for untreated and treated Cdk5 CKO1 mice from P30 to P60. Survival rate for treated mice $(n=16)$ is better than that of untreated mice $(n=13)$. (B) Average body weights of untreated $(n=3)$ and treated $(n=3)$ male Cdk5 cKO1 mice and littermate male Cdk5 ${ }^{f / f}$ (control) mice $(\mathrm{n}=3)$ at P60. ${ }^{*} \mathrm{P}<0.05$. (C), (D) Immunohistochemical (IHC) analyses of control, untreated, and treated Cdk5 cKO1 mice in cerebral cortex (C) and hippocampus (D) at P60. Coronal sections from these mice were stained with antibodies for NeuN, GFAP and Iba1. Scale bar = 100 $\mu$ m. (E-G) Bar graphs indicate average cell densities of neurons (E), activated astrocytes (F) and microglia cells (G) in control, untreated and treated Cdk5 cKO1 mice at $P 60$. ${ }^{* * *} P<0.001$ between control versus $C d k 5$ CKO1. $+P<0.05 ; \neq P<0.01 ; \S P<0.001$ between no treated versus treated (t-test).

as compared with untreated $\mathrm{Cdk} 5 \mathrm{cKO} 1$ or control mice at P60 (Additional file 5: Movie S1).

\section{Decreased Cdk5 and p35 protein expression and Cdk5} kinase activity in brain of Cdk5 cKO2 and dKO mice To generate Cdk5 cKO; tPA KO mice (dKO), we crossed Cdk5 cKO2 $\left(\mathrm{Cdk}^{\mathrm{f} /-}\right.$; CamKII-Cre $\left.{ }^{+}\right)$with tPA knockout mice $\left(\mathrm{tPA}^{-/-}\right.$) (Additional file 1: Figure S1). Both Cdk5 cKO2 and $\mathrm{dKO}$ mice were born with an expected
Mendelian frequency. Both $\mathrm{Cdk} 5 \mathrm{cKO} 2$ and $\mathrm{dKO}$ mice were indistinguishable from the control littermates at birth although some of the Cdk5 cKO2 and dKO mice were born dead. Surprisingly, we observed that nearly $95 \%$ of dKO mice died within a week after weaning (P21), similar to the trend we observed in Cdk5 cKO2 [10]. We measured their body weights at P17 and found a significant decrease in body weight gain in the $\mathrm{Cdk} 5 \mathrm{cKO} 2$ and $\mathrm{dKO}$ mice as compared to the control mice. Interestingly, 
body weights of the $\mathrm{dKO}$ mice were significantly higher in comparison to the $\mathrm{Cdk} 5 \mathrm{cKO} 2$ mice suggesting a partial rescue in body weight loss in the $\mathrm{dKO}$ mice (Figure 2A and $\mathrm{B}$ ). On the other hand, $\mathrm{TPA} \mathrm{KO}$ mice did not show any changes in survival rate and body weight gain in comparison with the control mice (data not shown).

We analyzed the Cdk5 mRNA levels in the brain cortex of P17 mice by using real-time PCR. We found that Cdk5 mRNA levels were significant decreased in both Cdk5 cKO2 and dKO mice as compared to the control mice (Figure 3A). Interestingly, Cdk5 mRNA levels of the $\mathrm{dKO}$ mice were significantly higher in comparison to the Cdk5 cKO2 mice, suggesting a partial rescue (Figure 3A). Additionally, we analyzed Cdk5 protein levels in the brain cortex of P17 mice by using Western blot analysis. Cdk5 protein levels were significantly decreased in both $\mathrm{Cdk} 5$ cKO2 and $\mathrm{dKO}$ mice as compared to the control mice (Figure 4A). Also, we performed IHC against Cdk5 and we found decreased expression of Cdk5 in neurons in the cortex of $\mathrm{Cdk} 5 \mathrm{cKO} 2$ and $\mathrm{dKO}$ mice as compared with control mice at P17 (black and blue arrow head Figure 3B left panel) suggesting that remaining Cdk5 positive cells observed in Cdk5 cKO2 and dKO were the glial cells or neuron cells in which Cre-mediated recombination was absent. Additionally, we analyzed the p35 protein levels by Western blot and found a significantly reduced expression in both $\mathrm{Cdk} 5 \mathrm{cKO} 2$ and $\mathrm{dKO}$ mice as compared with the control mice. Remarkably, the p35 protein levels were significantly higher in $\mathrm{dKO}$, in comparison with those in Cdk5 cKO2 mice, suggesting again a partial rescue in $\mathrm{dKO}$ mice (Figure 4B). Since the p35 expression is a limiting factor for Cdk5 kinase activity [22], we determined whether Cdk5 kinase activity was affected in the brain cortex of mice at P17. We found a significant decrease in Cdk5 kinase activity in cKO2 and $\mathrm{dKO}$ mice, as compared with the control mice. Interestingly, Cdk5 kinase activity was significantly higher in $\mathrm{dKO}$ in comparison with the
Cdk5 cKO2 mice, suggesting a partial rescue in the dKO mice (Figure 4C).

\section{Increased neuronal loss and reduced astrogliosis in brain of dKO mice}

We earlier reported that $\mathrm{Cdk} 5 \mathrm{cKO} 2$ mice displayed neuronal loss and increased astrogliosis as determined by the NeuN and GFAP protein levels, respectively [10]. To evaluate whether tPA deficiency in the background of Cdk5 cKO2 mice could improve this phenotype, we analyzed neuronal loss as detected by Nissl staining and NeuN expression, and astrogliosis detected by GFAP protein expression in coronal brain sections of control, Cdk5 cKO2, and dKO mice at P17. We found that both Cdk5 cKO2 and dKO mice showed a decreased Nissl staining (Figure 5A) and also a reduced NeuN expression measured by IHC (Figure $5 \mathrm{~B}$ ) as compared with the control mice. In addition, we found significantly decreased NeuN protein levels in both Cdk5 cKO2 and $\mathrm{dKO}$ brain cortex, as compared with the controls at P17 (Figure 5D). We also evaluated astrogliosis by IHC and the Western blot of GFAP in these mice. As reported earlier [10], we found increased GFAP staining by IHC; and a significant increase in GFAP protein expression by Western blot analysis in the brain cortex of Cdk 5 cKO2 mice as compared with the control mice. Surprisingly, the levels of GFAP in the $\mathrm{dKO}$ mice were reversed to near normal levels (Figure 5C and E) suggesting a partial reversal in the gliosis in these mice.

\section{Increased microgliosis and pro-inflammatory cytokines in the brain of dKO mice}

We had reported earlier increased microglia activation measured by F4/80 marker and CD68 mRNA levels in the forebrain of Cdk5 cKO1 mice at two to three months old [10]. To extend these observations to the Cdk5 cKO2 and dKO mice, we evaluated the CD68 mRNA levels and Iba1
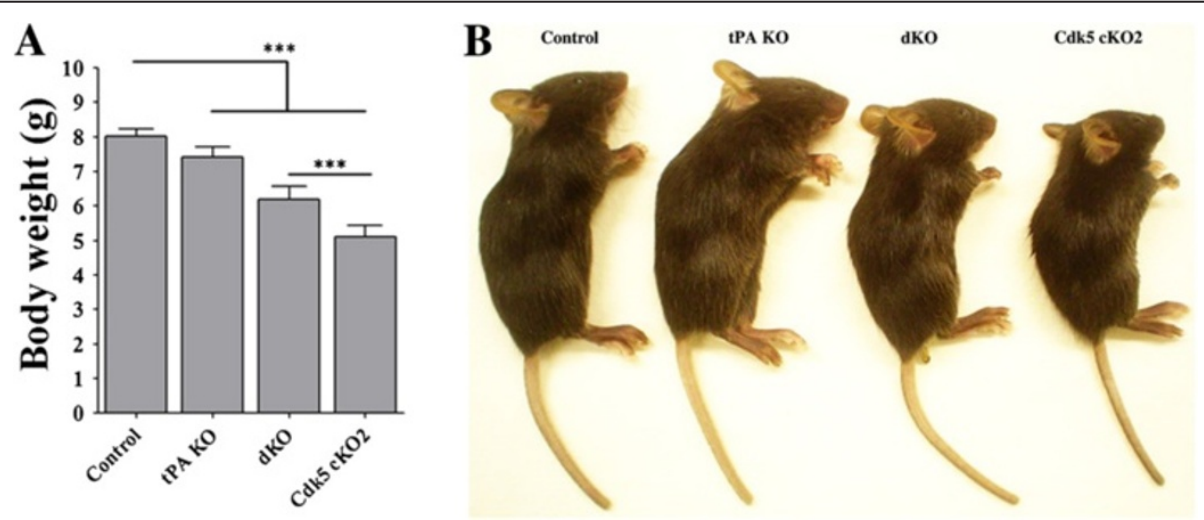

Figure 2 Generation of Cdk5 cKO2; tPA KO (dKO) mice. (A) Body weights of 17-day-old mice of four different genotypes. (B) Representative images of control, tPA KO, Cdk5 CKO2 and dKO mice. All data are presented as the mean and SEM ( $n=6$ to 12 mice per group), ***P $P 0.001$ (t-test). 

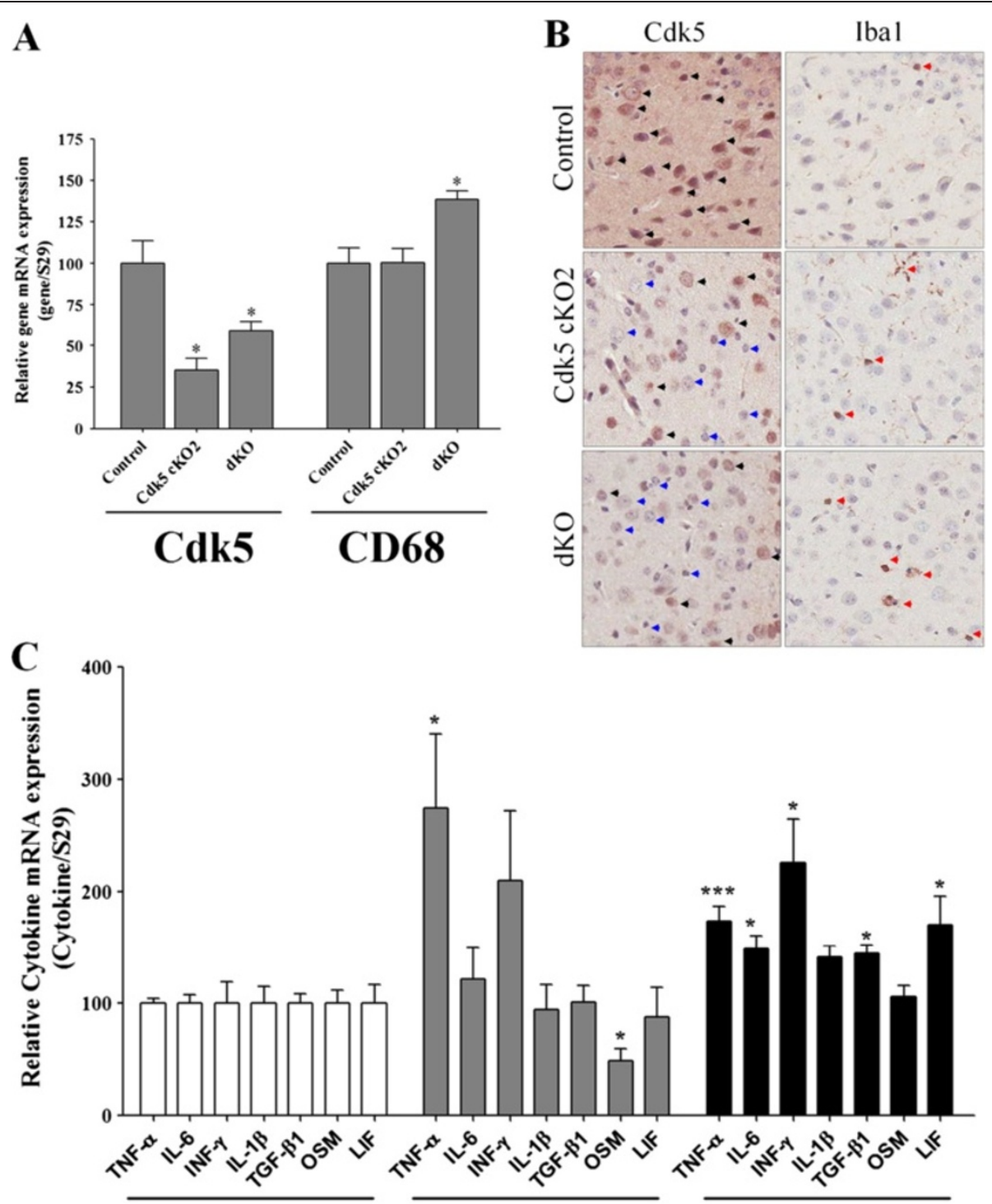

Control

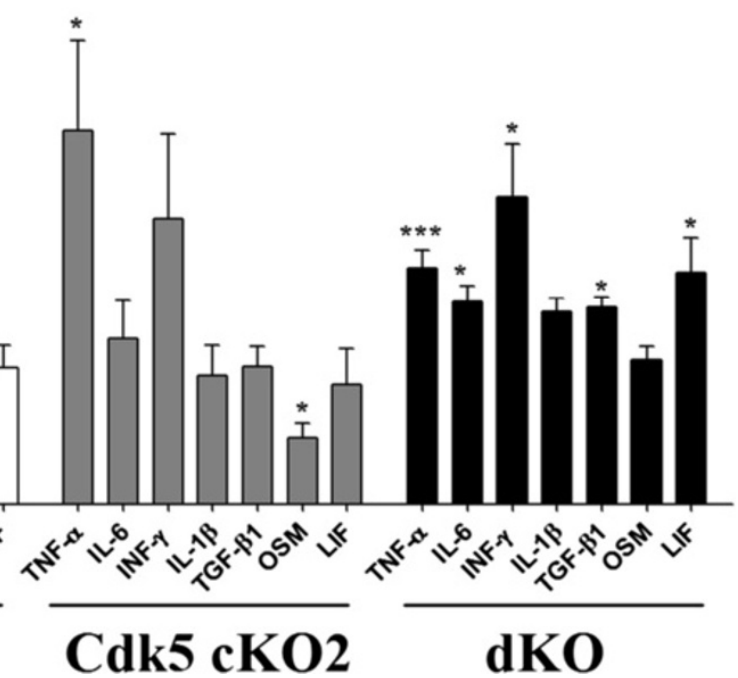

Figure 3 Increased microgliosis and pro-inflammatory cytokines in the brain of dKO mice. (A) qPCR analysis of Cdk5 and CD68 mRNA levels (a marker of activated microglia) normalized against S29. Total RNA was obtained from brain cortex of control, Cdk5 cKO2 and dKO mice at P17. There was a decreased Cdk5 mRNA levels on Cdk5 cKO2 and dKO mice. In contrast, CD68 was increased only on dKO mice as compared with control mice. (B) Right panel shows a representative IHC against Cdk5 and left panel an IHC against Iba1 of cortex coronal section from control, Cdk5 cKO2 and dKO mice at P17. Decreased Cdk5 expression was observed in the cortex of Cdk5 cKO2 and dKO mice (Blue head arrows as compared with black head arrows). IHC Iba1 shows that Iba1 positive cells are few in the cortex of the control mice as compared with Cdk5 CKO2 and dKO mice (red head arrows). Also, Iba1 positive cells are more apparent on dKO as compared with Cdk5 cKO2 mice. (C) Real-time PCR analysis of mRNA levels of several pro-inflammatory cytokines normalized against S29. All data are presented as the mean and SEM ( $n=3$ to 5$)$. ${ }^{*} P<0.05 ;{ }^{* * *} P<0.001$ (t-test)

protein expression in the brain cortices of these mice. At P17 the CD68 mRNA levels were similar in both the control and Cdk5 cKO2 mice. However, these levels were significantly increased in $\mathrm{dKO}$ mice as compared with the control and Cdk5 cKO2 mice (Figure 3A). Additionally, we evaluated whether $\mathrm{Cdk} 5$ deletion in the brain cortex of Cdk5 cKO2 and dKO mice could increase Iba1 positive cells by using IHC (Figure 3B). We found that in the same areas of the cortex of $\mathrm{Cdk} 5 \mathrm{cKO} 2$ mice where $\mathrm{Cdk} 5$ was deleted (black and blue head arrow Figure 3B left panel), there was an increase of Iba1 positive cells as compared with control mice (red head arrow, Figure $3 \mathrm{~B}$ right panel). Remarkably, we found more Iba1 positive cells on cortex of $\mathrm{dKO}$ mice as compared with $\mathrm{Cdk} 5 \mathrm{cKO} 2$ mice suggesting increased microglial activation in the $\mathrm{dKO}$ mice (Figure 3B right panel). As reported earlier, the 


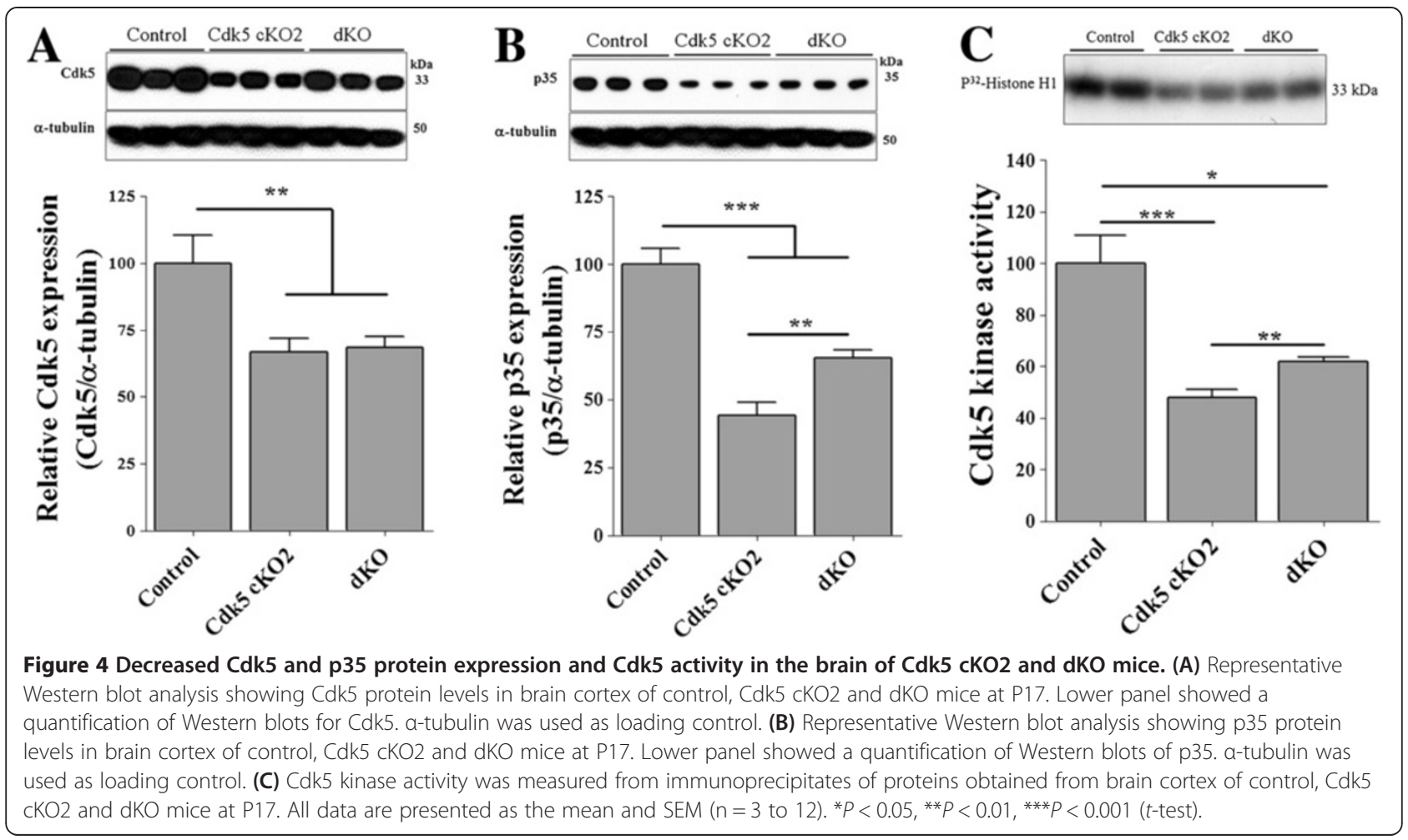

TNF- $\alpha$ levels were increased in Cdk5 cKO1 mice at two to three months old [10]. To extend these observations to the $\mathrm{Cdk} 5 \mathrm{cKO} 2$ and dKO mice, we evaluated several pro-inflammatory cytokines mRNA levels in the brain cortex of control, Cdk5 cKO2 and dKO mice at P17. We evaluated the expression of pro-inflammatory cytokines such as TNF- $\alpha$, IL-6, IFN- $\gamma$, IL- $1 \beta$, TGF- $\beta 1$, OSM, and LIF in the brain cortices of mutant and control mice at P17. Real-time PCR analysis with specific primers for all of the indicated cytokines revealed that only TNF- $\alpha$ mRNA levels were significantly increased, and OSM mRNA levels were decreased in Cdk5 cKO2, as compared with the control mice (Figure 3C). Most importantly, we found that mRNA levels of TNF- $\alpha$, IL-6, IFN- $\gamma$, TGF- $\beta 1$, and LIF were significantly increased in the $\mathrm{dKO}$ mice as compared with the control mice (Figure $3 \mathrm{C}$ ), suggesting that increased glial activation induced higher levels of cytokines in $\mathrm{dKO}$ mice.

\section{Discussion}

The conditional deletion of neuronal Cdk5 in the adult forebrain caused activation of astrocytes and microglia and neuroinflammation, and a subsequent neuronal loss and early lethality. In our first approach to suppress neuroinflammation in these mice, treatment with PPAR $\gamma$ agonist pioglitazone resulted in a significant reduction in microgliosis, astrogliosis, and neuronal loss associated with a better survival rate. In the second approach, we evaluated the potential role of tPA in neuroinflammation in Cdk 5 cKO mice by generating $\mathrm{dKO}$ mice in which the $t P A$ gene was deleted. The deletion of tPA in the Cdk5 KO mice caused a partial rescue in astrogliosis, although there was increased microgliosis and inflammatory cytokines levels. Nevertheless, the dKO mice still died at P21 similar to the Cdk5 cKO2 mice, suggesting that tPA does not play a major role in the etiology of neuroinflammation.

Differences in the longevity rate between the $\mathrm{Cdk} 5$ cKO1 and cKO2 mice are because the cKO2 mice have significantly reduced $\mathrm{Cdk} 5$ protein levels, as compared with Cdk5 cKO1 mice [10]. Cdk5 cKO2 mice have one allele knocked out in all cells of the body whereas another allele is deleted only in adult forebrain neurons. However, in Cdk5 cKO1 mice both alleles are deleted only in adult forebrain neurons, suggesting that expression levels of Cdk5 have a greater impact on the survival rate of these mice. Our results confirm several earlier reports indicating that $\mathrm{Cdk} 5$ kinase activity is required for survival of neurons under stressful conditions [23-26]. Cdk5 is known to prevent neuronal apoptosis by negative regulation of JNK [23]. It is also involved in the regulation of Akt activity mediating neuronal survival [24]. Cdk5 also plays critical roles in non-neuronal cells, such as oligodendrocytes and astrocytes. Thus, Cdk5 regulates oligodendrocytes differentiation and myelin repair [27-30]. Moreover, it was shown that Cdk5/p35 is expressed in astrocytes and it regulates the process of 

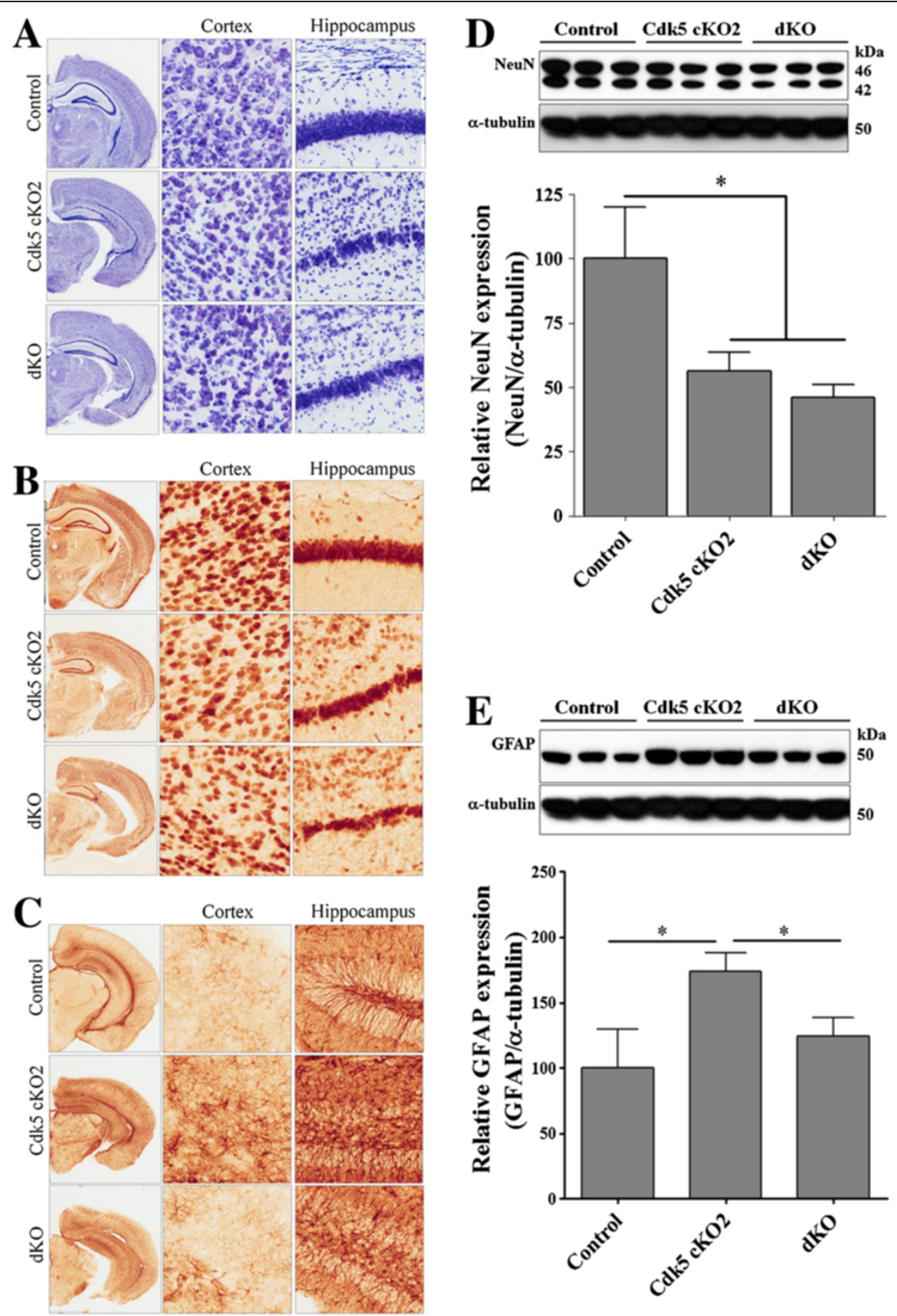

Figure 5 Increased neuronal loss and partial rescue of astrogliosis in the brain of dKO mice. (A) Nissl staining of coronal brain sections of control, Cdk5 CKO2 and dKO mice at P17. In higher magnification we observed a decreased of the number of cells on cortex and hippocampus of Cdk5 CKO2 and dKO mice. (B) Immunohistochemistry ( $\mathrm{HCC}$ against NeuN, a marker of neurons, of coronal brain sections of control, Cdk5 cKO2 and $\mathrm{dKO}$ mice at P17. In higher magnification we observed a decreased of the number of NeuN positive cells on cortex and hippocampus of Cdk5 CKO2 and dKO mice. (C) IHC against GFAP, a marker of astrogliosis, of coronal brain sections of control, Cdk5 cKO2 and dKO mice at P17. In higher magnification we observed an increased number of GFAP positive cells on cortex and hippocampus of Cdk5 cKO2. In contrast, there were a decreased number of GFAP positive cells on the same areas of brain of dKO mice. (D) Representative Western blot analysis showing NeuN protein levels in brain cortex of control, $\mathrm{Cdk} 5 \mathrm{cKO} 2$ and dKO mice at P17. Lower panel showed a quantification of Western blots of NeuN. a-tubulin was used as loading control. (E) Representative Western blot analysis showing GFAP protein levels in brain cortex of control, Cdk5 CKO2 and dKO mice at P17. Lower panel showed a quantification of Western blots of GFAP. a-tubulin was used as loading control. All data are presented as the mean and SEM ( $n=3$ to 6$) .{ }^{*} P<0.05$ (t-test). 
elongation of the scratched astrocytes [31]. Here, we found neuroinflammation without neuronal loss at P30 in Cdk5 cKO1 mice. However, we observed pathological changes in neurons by silver staining at P30, indicating that neuroinflammation might trigger neuronal degeneration, which could be contributing to the neuronal loss at late stages. Interestingly, we found an increased astrogliosis and neuronal loss much early in the cerebral cortex of Cdk 5 cKO2 (P17) in comparison with Cdk5 cKO1 mice (P30), which suggests that the decreased Cdk5 levels in $\mathrm{Cdk} 5 \mathrm{cKO} 2$ mice accelerate neuroinflammation with a consequent neuronal loss and an early lethality.

PPAR $\gamma$ agonists inhibit the production of many inflammatory cytokines such as TNF- $\alpha$, IL- $1 \beta$ and IL- 6 in several cell types, including monocytes, macrophages and epithelial cells [32]. This inhibitory effect occurred through silencing the action of the transcription factors, NFKB and AP-1, on the promoters of the cytokines and others genes [32-34]. On the other hand, microglia are derived from hematopoietic precursors that enter the developing CNS to become a major population of resident macrophages in brain. PPAR $\gamma$ agonists can potentially control neuroinflammation through their actions on the activated microglia which can produce, similar to peripheral macrophages, pro-inflammatory and neurotoxic factors, including cytokines, reactive oxygen intermediates, and nitric oxide [35]. PPAR $\gamma$ agonist pioglitazone has been reported to have beneficial effects on neurodegenerative disease mouse models [36-38]. Thus, the pioglitazone treatment seems to offer a broad range of potentially protective properties that attenuate the chronic neuroinflammation and oxidative stress that is responsible for the progression of PD [36]. Pioglitazone treatment also has inhibitory effects on STAT3 activation in ALS mouse models [37]. Additionally, it was reported that pioglitazone treatment of amyloid precursor protein/presenilin 1 mice (an AD mouse model) enhanced the microglial uptake of $A \beta$ and spatial cognitive memory improvement [38]. Here, we have found that pioglitazone treatment suppressed neuroinflammation by reducing activation of microglia and astrocytes in Cdk5 cKO1 mice. Indeed, we found that pioglitazone treatment can improve the neurological deficit observed in Cdk 5 cKO1 mice. Similarly, the survival rate and body weight gain was significantly increased in the Cdk5 cKO1 mice treated with pioglitazone as compared to the untreated Cdk5 cKO1 mice. These results suggest that a decrease in neuronal Cdk 5 expression produces an increased neuroinflammation, resulting in neuronal loss and death.

In addition to the effects of PPAR $\gamma$ agonists on PPAR $\gamma$ activity, it was recently demonstrated that troglitazone, another PPARY agonist, decreased tau-Thr231 phosphorylation [39]. This repression was brought about by inhibition of the Cdk5 kinase activity caused by an inhibition of proteasomal degradation of p35 in human neuroblastoma SH-SY5Y cells and rat primary cortical neurons in culture [39]. Moreover, altered Cdk5 activity has been associated with many neurodegenerative diseases, which is mainly regulated by the increased proteolysis of p35 into p25, with a subsequent increased Cdk5 kinase activity [40-42]. Therefore, the beneficial effects of PPAR $\gamma$ agonist treatment in neurodegenerative diseases could be due to inhibition of Cdk5 kinase activity and a subsequent reduction in tau phosphorylation. Additionally, it will be of interest to explore potential beneficial effects of these agonists for treating painful disorders since Cdk5 has also been implicated in pain signaling [6].

Two important questions that need to be answered are: How microglia and astrocytes are activated? And which molecules released from neurons are activating microglia and astrocytes in Cdk5 cKO mice? In our previous work, we found increased tPA mRNA levels and tPA activity in Cdk5 cKO1 mice [10] and because neurons are known to release tPA and activate microglia through annexin II [43], we therefore evaluated here whether tPA plays a major role in neuroinflammation and neuronal loss observed on Cdk5 cKO mice. Additionally, it was reported that tPA can exert neurotoxic effects in a catalytic-independent way by activating the ERK1/2 signaling pathway and that this molecular mechanism could be responsible for the neuronal death induced in mouse hippocampal neurons after $A \beta$ treatment [44]. Moreover, the same group also reported that $A \beta$ treatment of tPA deficient glial cells results in a dramatic reduction of inflammation analyzed by TNF- $\alpha$ expression [45]. Here, we generated $\mathrm{dKO}$ mice that lack tPA in all cells and Cdk5 in forebrain neurons. In these mice, we found a partial rescue in astrogliosis, but not in microgliosis. We also observed increased CD68 mRNA levels and increased Iba1 positive cells, markers of microgliosis, in $\mathrm{dKO}$ mice. In contrast, it was reported that tPA treatment did not increase Ibal expression on microglia from mouse spinal cord [46], suggesting an unknown mechanism of microglia activation caused by a deficiency of tPA. Finally, we found elevated levels of inflammatory cytokines in $\mathrm{dKO}$ mice in comparison with control mice, suggesting that the increased expression of tPA observed in the Cdk5 cKO1 mice does not contribute significantly to the pathological process that leads to neuroinflammation, neuronal loss and early lethality.

\section{Conclusion}

We have demonstrated that tPA does not play a major role in the etiology of neuroinflammation seen in Cdk5 cKO mice; however, the treatment with pioglitazone significantly reduced the microgliosis, astrogliosis, and neuronal loss and improved the neurological deficit in Cdk5 cKO mice suggesting a beneficial effect of this PPAR $\gamma$ agonist in treating neurodegenerative diseases. 


\section{Additional files}

Additional file 1: Figure $\mathbf{S 1}$. Generation of Cdk5 CKO2, tPA KO mice $\mathrm{Cdk} 5$ floxed $\left(\mathrm{Cdk} 5^{\mathrm{f} / \mathrm{f}}\right)$ mice were crossed with tPA knockout mice (tPA KO) to generate $\mathrm{Cdk}^{\mathrm{f} / \mathrm{f}} ; \mathrm{tPA}^{+/-}$mice. In addition, $\mathrm{Cdk} 5^{+/-}$mice [7] were crossed with either CamKlla-Cre ${ }^{+}[17]$ and tPA KO mice to generate $\mathrm{Cdk}^{+/-}$; CamKIlla-Cre ${ }^{+}$and $\mathrm{Cdk}^{+/-}$; tPA KO mice, respectively. Lately, $\mathrm{Cdk}^{+/-}$; CamKIla-Cre ${ }^{+}$mice were crossed either with $\mathrm{Cdk}^{\mathrm{f} / \mathrm{f}} ; \mathrm{tPA}^{+/-}$and $\mathrm{Cdk5}^{+/-}$: tPA KO mice to generate $\mathrm{Cdk5}^{\mathrm{f} /-}$; CaMKlla-Cre ${ }^{+} ; \mathrm{tPA}^{+/-}$and $\mathrm{Cdk5}^{+/-}$; CamKIlla-Cre $; \mathrm{tPA}^{+/-}$. Finally, these mice were crossed to generate $\mathrm{Cdk}^{\mathrm{f} /-}$; CamKlla-Cre; $\mathrm{tPA}^{+/-}$(control mice), $\mathrm{Cdk}^{\mathrm{f} / \text {; }}$ $\mathrm{CamKIla}^{-} \mathrm{Cre}^{+} ; \mathrm{tPA}^{+--}(\mathrm{Cdk} 5 \mathrm{CKO} 2$ mice $)$ and $\mathrm{Cdk}^{\mathrm{f} /}$; CamKlla-Cre $^{+}$. $\mathrm{tPA}^{-1-}$ (dKO mice)

Additional file 2: Figure S2. Inflammation proceeds neuronal loss in Cdk5cKO mice. (A, B) IHC analysis of coronal brain sections of P21 day-old mice. Sections of cerebral cortex (A) and hippocampus (B) from control and Cdk5 cKO1 mice were stained with antibodies for NeuN, GFAP and Iba1. Scale bar $=100 \mu \mathrm{m}$. (C-E) Bar graphs of average cell densities of neuron (C), activated astrocytes (D) and microglia (E) in each brain region of Cdk5 cKO1 mice and littermate controls at P21. (F, G) $I H C$ analysis of coronal brain sections of P30 day-old mice. Sections of cerebral cortex (F) and hippocampus (G) of the control and Cdk5 CKO1 mice were stained with antibodies for NeuN, GFAP and Iba1. Scale bar $=100 \mu \mathrm{m}$. (H-J) Bar graphs of average cell densities of neurons $(\mathrm{H})$ activated astrocytes (I) and microglia $(J)$ in each brain region of $\mathrm{Cdk5}$ CKO1 mice and littermate controls at P30. ${ }^{* * P}<0.01 ;{ }^{* *} \mathrm{P}<0.001$ (t-test).

Additional file 3: Figure S3. Evaluation of degenerative neurons and neuron size on coronal brain section of Cdk5 CKO1 mice. (A) Degenerative neurons were evaluated by amino-cupric silver stain of different areas of the brain control and Cdk5 cKO1 mice at P30. Increase number of amino-cupric silver positive cells (brown) on cerebral cortex and striatum of $\mathrm{Cdk} 5 \mathrm{CKO} 1$ in comparison with control mice. (B) Representative coronal sections stained with a red fluorescent Nissl stain (NeuroTraceTM530/615) to evaluated neuronal size in control and Cdk5 CKO1 mice. No difference in neuronal size was found in CA1 pyramidal neurons between Cdk5 cKO1 and control littermates at P30. Bar graphs indicate average of neuronal size of neurons from control and Cdk5 cKO1 mice.

Additional file 4: Figure S4. PPARy agonist pioglitazone treatment suppresses neuroinflammation and reverses neuronal loss in Cdk5 cKO1 mice at P90. (A) Survival curves for untreated and treated Cdk5 CKO1 mice from P30 to P90. Survival rate for treated mice $(n=4)$ is better than that of untreated mice $(n=4)$. $(P=0.029$ in Log-rank test and $P=0.030$ in Wilcoxon test). (B) Average body weights of untreated $(n=4)$ and treated $(\mathrm{n}=3)$ Cdk5 cKO1 male mice and littermate male Cdk5f/f (control) mice $(n=4)$ at P90. ${ }^{*} P<0.05$; ${ }^{* * P}<0.01$ (t-test). (C, D) $I H C$ cortex sections of the control, untreated, and treated Cdk5 CKO1 mice o (C) and hippocampus (D) at P90. Coronal sections from these mice were stained with antibodies for NeuN, GFAP and Iba1. Scale bar = $100 \mu \mathrm{m}$. (E-G) Bar graphs indicate average cell densities of neurons (E), activated astrocytes (F) and microglia cells (G) in control, untreated and treated Cdk5 CKO1 mice at P90. ${ }^{*} \mathrm{P}<0.05$; ${ }^{* * P}<0.01 ;{ }^{* *} \mathrm{P}<0.001$ between control versus Cdk5 cKO1. $+\mathrm{P}<0.05 ; \neq \mathrm{P}<0.01 ; \S \mathrm{P}<0.001$ between untreated versus treated.

Additional file 5: Movie S1. Partial improvement in abnormal limb retraction and tremors in C $d k 5$ conditional knockout mice treated with Pioglitazone.

\section{Abbreviations}

Aß: amyloid beta; AD: Alzheimer's disease; CaMKIl: calcium/calmodulindependent kinase II; Cdk: cyclin-dependent kinase; CKO: conditional knockout; CNS: central nervous system; DAPI: 4',6-diamidino-2-phenylindole; dKO: double knockout; EDTA: ethylenediaminetetraacetic acid; GFAP: glial fibrillary acidic protein; HRP: horse radish peroxidase; Iba1: ionized calcium binding adaptor molecule 1; IgG: immunoglobulin G;

IHC: Immunohistochemical; IL-1ß: interleukin-1 beta; IL-6: interleukin-6; IP: immunoprecipitated proteins; JNK: Jun N-terminal kinase; LIF: leukemia inhibitory factor; NeuN: neuronal nuclei NFkB: nuclear factor kappa B; O.C. T.: optimal cutting temperature; OSM: oncostatin M; PBS: phosphate buffered saline; PCR: polymerase chain reaction; PPAR: peroxisome proliferatoractivated receptor; SDS: sodium dodecyl sulfate; STAT3: signal tranducer and activator of transcription 3; TGF- $\beta 1$ : transforming growth factor $\beta 1$; TNF-a: tumor necrosis factor alpha; tPA: tissue-type plasminogen activator; Triton X-100: polyoxyethylene(10) octyl phenyl ether.

\section{Competing interests}

The authors declare that they have no competing interests.

\section{Authors' contributions}

EU, TO, ABK designed research; EU, RH, MP, AT, ST, TO and ABK performed research; EU, $\mathrm{RH}, \mathrm{MP}, \mathrm{TO}$, and $\mathrm{ABK}$ analyzed data, and $\mathrm{EU}, \mathrm{TO}$ and $\mathrm{ABK}$ wrote the paper. All authors read and approved the final manuscript.

\section{Acknowledgments}

We thank Dr. M Heneka for his technical advice and Lawrence Jones for his expert editorial assistance. This work was supported by the Division of Intramural Research, NIDCR, NIH, and PAI 79100009 and Fondecyt 11110136 (to EU).

\section{Author details}

Functional Genomics Section, Laboratory of Cell and Developmental Biology, National Institute of Dental and Craniofacial Research, National Institutes of Health, Bethesda, MD, USA. ${ }^{2}$ Department of Life Science and Medical Bioscience, Waseda University, Tokyo, Japan. ${ }^{3}$ Department of Pediatrics, Asahikawa Medical College, Asahikawa, Hokkaido, Japan. ${ }^{4}$ Current address: Biology Department, Faculty of Science, University of Chile, Santiago, Chile.

Received: 17 September 2013 Accepted: 21 January 2014

Published: 5 February 2014

\section{References}

1. Dhavan R, Tsai LH: A decade of CDK5. Nat Rev Mol Cell Biol 2001, 2:749-759.

2. Lew J, Huang QQ, Qi Z, Winkfein RJ, Aebersold R, Hunt T, Wang JH: A brainspecific activator of cyclin-dependent kinase 5. Nature 1994, 371:423-426.

3. Dhariwala FA, Rajadhyaksha MS: An unusual member of the Cdk family: Cdk5. Cell Mol Neurobiol 2008, 28:351-369.

4. Borquez DA, Olmos C, Alvarez S, Di Genova A, Maass A, Gonzalez-Billault C: Bioinformatic survey for new physiological substrates of Cyclin-dependent kinase 5. Genomics 2013, 101:221-228.

5. Contreras-Vallejos E, Utreras E, Gonzalez-Billault C: Going out of the brain: non-nervous system physiological and pathological functions of Cdk5. Cell Signal 2012, 24:44-52.

6. Utreras E, Futatsugi A, Pareek TK, Kulkarni AB: Molecular roles of Cdk5 in pain signaling. Drug Discov Today 2009, 6:105-111.

7. Ohshima T, Ward JM, Huh CG, Longenecker G, Veeranna, Pant HC, Brady RO, Martin LJ, Kulkarni AB: Targeted disruption of the Cyclin-dependent kinase 5 gene results in abnormal corticogenesis, neuronal pathology and perinatal death. Proc Natl Acad Sci U S A 1996, 93:11173-11178.

8. Ohshima T, Hirasawa M, Tabata H, Mutoh T, Adachi T, Suzuki H, Saruta K, Iwasato T, Itohara S, Hashimoto M, et al: Cdk5 is required for multipolar-tobipolar transition during radial neuronal migration and proper dendrite development of pyramidal neurons in the cerebral cortex. Development 2007, 134:2273-2282.

9. Hirasawa M, Ohshima T, Takahashi S, Longenecker G, Honjo Y, Veeranna, Pant HC, Mikoshiba K, Brady RO, Kulkarni AB: Perinatal abrogation of Cdk5 expression in brain results in neuronal migration defects. Proc Natl Acad Sci U S A 2004, 101:6249-6254.

10. Takahashi S, Ohshima T, Hirasawa M, Pareek TK, Bugge TH, Morozov A, Fujieda K, Brady RO, Kulkarni AB: Conditional deletion of neuronal cyclindependent kinase 5 in developing forebrain results in microglial activation and neurodegeneration. Am J Pathol 2010, 176:320-329.

11. Heneka MT, Sastre M, Dumitrescu-Ozimek L, Hanke A, Dewachter I, Kuiperi C, O'Banion K, Klockgether T, Van Leuven F, Landreth GE: Acute treatment with the PPARgamma agonist pioglitazone and ibuprofen reduces glial inflammation and Abeta1-42 levels in APPV717I transgenic mice. Brain 2005, 128:1442-1453.

12. Niino M, Iwabuchi K, Kikuchi S, Ato M, Morohashi T, Ogata A, Tashiro K, Onoe K: Amelioration of experimental autoimmune encephalomyelitis in 
C57BL/6 mice by an agonist of peroxisome proliferator-activated receptor-gamma. J Neuroimmunol 2001, 116:40-48.

13. Diab A, Deng C, Smith JD, Hussain RZ, Phanavanh B, Lovett-Racke AE, Drew $P D$, Racke MK: Peroxisome proliferator-activated receptor-gamma agonist 15-deoxy-Delta(12,14)-prostaglandin J(2) ameliorates experimental autoimmune encephalomyelitis. J Immunol 2002, 168:2508-2515.

14. Feinstein DL, Galea E, Gavrilyuk V, Brosnan CF, Whitacre CC, Dumitrescu-Ozimek L, Landreth GE, Pershadsingh HA, Weinberg G, Heneka MT: Peroxisome proliferator-activated receptor-gamma agonists prevent experimental autoimmune encephalomyelitis. Ann Neurol 2002, 51:694-702

15. Natarajan C, Bright JJ: Peroxisome proliferator-activated receptor-gamma agonists inhibit experimental allergic encephalomyelitis by blocking IL-12 production, IL-12 signaling and Th1 differentiation. Genes Immun 2002, 3:59-70.

16. Breidert T, Callebert J, Heneka MT, Landreth G, Launay JM, Hirsch EC: Protective action of the peroxisome proliferator-activated receptorgamma agonist pioglitazone in a mouse model of Parkinson's disease. J Neurochem 2002, 82:615-624.

17. Dragatsis I, Zeitlin S: CaMKIlalpha-Cre transgene expression and recombination patterns in the mouse brain. Genesis 2000, 26:133-135.

18. Huang YY, Bach ME, Lipp HP, Zhuo M, Wolfer DP, Hawkins RD, Schoonjans $L$, Kandel ER, Godfraind JM, Mulligan R, et al: Mice lacking the gene encoding tissue-type plasminogen activator show a selective interference with late-phase long-term potentiation in both Schaffer collateral and mossy fiber pathways. Proc Natl Acad Sci U S A 1996, 93:8699-8704.

19. Andres M, Andre VM, Nguyen S, Salamon N, Cepeda C, Levine MS, Leite JP, Neder L, Vinters HV, Mathern GW: Human cortical dysplasia and epilepsy: an ontogenetic hypothesis based on volumetric MRI and NeuN neuronal density and size measurements. Cereb Cortex 2005, 15:194-210.

20. Utreras E, Keller J, Terse A, Prochazkova M, ladarola MJ, Kulkarni AB: Transforming growth factor-beta 1 regulates $\mathrm{Cdk} 5$ activity in primary sensory neurons. J Biol Chem 2012, 287:16917-16929.

21. Utreras E, Futatsugi A, Rudrabhatla P, Keller J, ladarola MJ, Pant HC, Kulkarn $A B$ : Tumor necrosis factor-alpha regulates cyclin-dependent kinase 5 activity during pain signaling through transcriptional activation of p35. J Biol Chem 2009, 284:2275-2284.

22. Takahashi S, Ohshima T, Cho A, Sreenath T, ladarola MJ, Pant HC, Kim Y, Nairn AC, Brady RO, Greengard P, Kulkarni AB: Increased activity of cyclindependent kinase 5 leads to attenuation of cocaine-mediated dopamine signaling. Proc Natl Acad Sci U S A 2005, 102:1737-1742.

23. Li BS, Zhang L, Takahashi S, Ma W, Jaffe H, Kulkarni AB, Pant HC: Cyclindependent kinase 5 prevents neuronal apoptosis by negative regulation of C-Jun N-terminal kinase 3. EMBO J 2002, 21:324-333.

24. Li BS, Ma W, Jaffe H, Zheng Y, Takahashi S, Zhang L, Kulkarni AB, Pant HC: Cyclin-dependent kinase- 5 is involved in neuregulin-dependent activation of phosphatidylinositol 3-kinase and Akt activity mediating neuronal survival. J Biol Chem 2003, 278:35702-35709.

25. O'Hare MJ, Kushwaha N, Zhang Y, Aleyasin H, Callaghan SM, Slack RS, Albert PR, Vincent I, Park DS: Differential roles of nuclear and cytoplasmic cyclin-dependent kinase 5 in apoptotic and excitotoxic neuronal death. J Neurosci 2005, 25:8954-8966.

26. Hisanaga S, Endo R: Regulation and role of cyclin-dependent kinase activity in neuronal survival and death. J Neurochem 2010, 115:1309-1321.

27. Miyamoto Y, Yamauchi J, Chan JR, Okada A, Tomooka Y, Hisanaga S, Tanoue A: Cdk5 regulates differentiation of oligodendrocyte precursor cells through the direct phosphorylation of paxillin. J Cell Sci 2007, 120:4355-4366.

28. He X, Takahashi S, Suzuki H, Hashikawa T, Kulkarni AB, Mikoshiba K, Ohshima $\mathrm{T}$ : Hypomyelination phenotype caused by impaired differentiation of oligodendrocytes in Emx1-cre mediated Cdk5 conditional knockout mice. Neurochem Res 2011, 36:1293-1303.

29. Bankston AN, Li W, Zhang H, Ku L, Liu G, Papa F, Zhao L, Bibb JA, Cambi F, Tiwari-Woodruff SK, Feng Y: p39, the primary activator for cyclin-dependent kinase 5 (Cdk5) in oligodendroglia, is essential for oligodendroglia differentiation and myelin repair. J Biol Chem 2013, 288:18047-18057.

30. Yang Y, Wang H, Zhang J, Luo F, Herrup K, Bibb JA, Lu R, Miller RH: Cyclin dependent kinase 5 is required for the normal development of oligodendrocytes and myelin formation. Dev Biol 2013, 378:94-106.
31. He Y, Li HL, Xie WY, Yang CZ, Yu AC, Wang Y: The presence of active Cdk5 associated with $\mathrm{p} 35$ in astrocytes and its important role in process elongation of scratched astrocyte. Glia 2007, 55:573-583.

32. Daynes RA, Jones DC: Emerging roles of PPARs in inflammation and immunity. Nat Rev Immunol 2002, 2:748-759.

33. Jiang C, Ting AT, Seed B: PPAR-gamma agonists inhibit production of monocyte inflammatory cytokines. Nature 1998, 391:82-86.

34. Ricote M, Li AC, Willson TM, Kelly CJ, Glass CK: The peroxisome proliferator-activated receptor-gamma is a negative regulator of macrophage activation. Nature 1998, 391:79-82.

35. Bernardo A, Minghetti L: PPAR-gamma agonists as regulators of microglial activation and brain inflammation. Curr Pharm Des 2006, 12:93-109.

36. Randy LH, Guoying B: Agonism of peroxisome proliferator receptor-gamma may have therapeutic potential for neuroinflammation and Parkinson's disease. Curr Neuropharmacol 2007, 5:35-46.

37. Shibata N, Yamamoto T, Hiroi A, Omi Y, Kato Y, Kobayashi M: Activation of STAT3 and inhibitory effects of pioglitazone on STAT3 activity in a mouse model of SOD1-mutated amyotrophic lateral sclerosis. Neuropathology 2010, 30:353-360.

38. Yamanaka M, Ishikawa T, Griep A, Axt D, Kummer MP, Heneka MT: PPARgamma/RXRalpha-induced and CD36-mediated microglial amyloid-beta phagocytosis results in cognitive improvement in amyloid precursor protein/presenilin 1 mice. J Neurosci 2012, 32:17321-17331.

39. Cho DH, Lee EJ, Kwon KJ, Shin CY, Song KH, Park JH, Jo I, Han SH: Troglitazone, a thiazolidinedione, decreases tau phosphorylation through the inhibition of cyclin-dependent kinase 5 activity in SH-SY5Y neuroblastoma cells and primary neurons. J Neurochem 2013, 126:685-695.

40. Utreras E, Maccioni R, Gonzalez-Billault C: Cyclin-dependent kinase 5 activator p35 over-expression and amyloid beta synergism increase apoptosis in cultured neuronal cells. Neuroscience 2009, 161:978-987.

41. Shukla V, Skuntz S, Pant HC: Deregulated Cdk5 activity is involved in inducing Alzheimer's disease. Arch Med Res 2012, 43:655-662.

42. Su SC, Tsai LH: Cyclin-dependent kinases in brain development and disease. Annu Rev Cell Dev Biol 2011, 27:465-491.

43. Siao CJ, Tsirka SE: Tissue plasminogen activator mediates microglial activation via its finger domain through annexin II. J Neurosci 2002, 22:3352-3358.

44. Medina MG, Ledesma MD, Dominguez JE, Medina M, Zafra D, Alameda F, Dotti CG, Navarro P: Tissue plasminogen activator mediates amyloidinduced neurotoxicity via Erk1/2 activation. EMBO J 2005, 24:1706-1716.

45. Pineda D, Ampurdanes C, Medina MG, Serratosa J, Tusell JM, Saura J, Planas AM, Navarro P: Tissue plasminogen activator induces microglial inflammation via a noncatalytic molecular mechanism involving activation of mitogen-activated protein kinases and Akt signaling pathways and AnnexinA2 and Galectin-1 receptors. Glia 2012, 60:526-540.

46. Berta T, Liu YC, Xu ZZ, Ji RR: Tissue plasminogen activator contributes to morphine tolerance and induces mechanical allodynia via astrocytic IL-1 beta and ERK signaling in the spinal cord of mice. Neuroscience 2013 247:376-385.

\section{doi:10.1186/1742-2094-11-28}

Cite this article as: Utreras et al:: Suppression of neuroinflammation in forebrain-specific Cdk5 conditional knockout mice by PPARY agonist improves neuronal loss and early lethality. Journal of Neuroinflammation 2014 11:28.

\section{Submit your next manuscript to BioMed Central and take full advantage of:}

- Convenient online submission

- Thorough peer review

- No space constraints or color figure charges

- Immediate publication on acceptance

- Inclusion in PubMed, CAS, Scopus and Google Scholar

- Research which is freely available for redistribution 